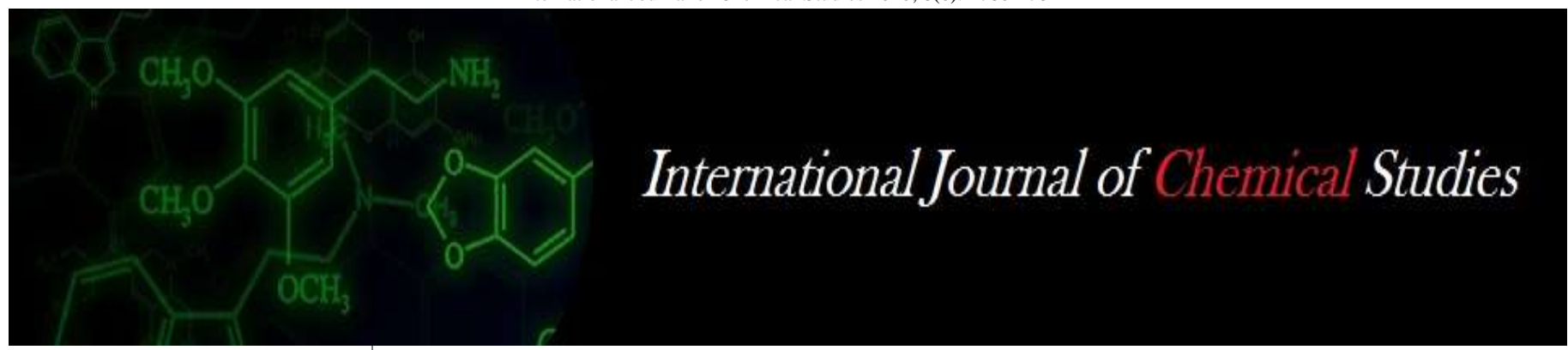

P-ISSN: 2349-8528

E-ISSN: 2321-4902

www.chemijournal.com

IJCS 2020; 8(6): 2780-2784

(C) 2020 IJCS

Received: 23-08-2020

Accepted: 03-10-2020

Venkata Reddy HK

M.Tech. (Agrl. Engg.)

Department of Farm Machinery and Power Engineering,

Kelappaji College of Agricultural Engineering and Technology,

Tavanur, Kerala, India

Jayan PR

Professor and Head, Department of Farm Machinery and Power

Engineering, Kelappaji College of Agricultural Engineering and Technology, Tavanur, Kerala, India
Corresponding Author: Venkata Reddy HK

M.Tech. (Agrl. Engg.), Department of Farm Machinery and Power Engineering, Kelappaji College of Agricultural Engineering and Technology, Tavanur, Kerala, India

\section{Investigation of soil properties affecting optimum design of pokkali paddy harvester}

\section{Venkata Reddy HK and Jayan PR}

DOI: https://doi.org/10.22271/chemi.2020.v8.i6an.11201

\begin{abstract}
The Pokkali field is a unique eco-system prevailing in the coastal tract of Kerala with rich bio diversity and amazing capacity to produce organic rice and shrimp alternatively. In the saline, water-logged Pokkali farm lands, rice and shrimps are farmed alternatively. During the time of harvest, the fields are almost dry and by the time of harvest, the fields become completely waterlogged. This shift in the moisture regime causes a great variation in the nutrient status of the Pokkali soil. Along with it, changes in soil $\mathrm{pH}$ and electrical conductivity play a role in the nutrient dynamics in these soils. The soil samples were collected from eight Pokkali padashekarams of Kottuvally panchayath and RRS, Vyttila Organic carbon, available nitrogen and magnesium showed a decreasing trend from mound preparation to harvest stage. The available nutrients namely $\mathrm{P}, \mathrm{K}, \mathrm{Ca}, \mathrm{S}, \mathrm{Fe}, \mathrm{B}, \mathrm{Al}$ and $\mathrm{Na}$ followed an increasing trend from mound preparation to harvest stage. Available $\mathrm{Zn}, \mathrm{Mn}$ and $\mathrm{Cu}$ did not show any significant difference between two stages. The study shows that the cone index and shear strength of Pokkali soils decreased with increased depth and decreased with increase in moisture content. For this soil the critical moisture content was found to be $45.9 \%$.
\end{abstract}

Keywords: Investigation, properties, Pokkali, soil, water logged

\section{Introduction}

The Pokkali field is a unique eco system prevailing in the coastal tract of Kerala with rich bio diversity and amazing capacity to produce organic rice and shrimp alternatively. Rice is grown during non-saline period and the farmers carry out shrimp culture during the saline phase with both having unique symbiotic benefits. Rice plants get their nutrients from the left over of the shrimps and the shrimps in turn, feed on the stalks and decaying remnants of the rice crop. Neither chemical fertilizers nor insecticides and pesticides are used. The usual ploughing and transplantation are not required for Pokkali. Pokkali areas lie in Trissur, Ernakulum and Alappuzha districts covering a total area of 8500 ha. It spreads over 34 Krishibhavans of these three districts. In the saline, water-logged pokkali farm lands, rice and shrimps are farmed alternatively. In more than $90 \%$ of the single cropped lands, rice cultivation is done during the low saline phase from May/June to September/October; the traditional prawn filtration is taken up during the high saline phase which sets in December/January. Generally manuring and plant protection operations are not necessary for pokkali farming systems. The crop matures at about 120 days. The ear heads alone are harvested, leaving the straw behind. The average yield of rice with traditional rice varieties is $1500 \mathrm{~kg} \mathrm{ha}^{-1}$. The conventional method of harvesting of pokkali paddy crop by using sickles. The various farming operations in Pokkali paddy cultivation, the harvesting is done by women labourers by walking on the swampy and marshy inundated paddy fields at waist-deep water, which is laborious, tedious and cumbersome.

Blake, G.R. and Hartge (1986) ${ }^{[5]}$ studied the physical properties of soil. They found out that the variation in bulk density is attributable to the relative proportion and specific gravity of organic and inorganic particles and its porosity. Most mineral soils had bulk densities between 1.0 and $2.0 \mathrm{~g} \mathrm{~cm}^{-3}$.

Grigal et al. (1989) studied about bulk density of surface soils and peat in the north central United States. They also mentioned that a very compacted soil perhaps due to tractor compaction would have a bulk density of 1.4 to $1.6 \mathrm{~g} \mathrm{~cm}^{3}$ and an open friable soil with good organic matter content will have a bulk density of $<1.0 \mathrm{~g} \mathrm{~cm}^{3}$. Although bulk densities are seldom measured they are very important in quantitative of soil and nutrient status of terrestrial ecosystem study. 
Adeniran and Babatunde (2010) ${ }^{[2]}$ conducted a study on investigation on wetland soil properties affecting optimum soil cultivation. A cone penetrometer and a shear vane apparatus $(19 \mathrm{~mm})$ were used to determine the cone index and the torque that cause the soil to shear at different moisture contents. The study showed that the cone index increased with depth and decreased with increase in moisture content. High moisture content reduced the soil cohesion. The internal frictional angle of the soil was 37.90. The following values were obtained for soil cohesion $112,62,38,30$ and $12 \mathrm{kN} . \mathrm{m}^{-2}$ respectively at moisture contents of $0,5,10,15$ and 20 percent. Moisture content between $10-15$ per cent (dry basis) appeared ideal for cultivation of the soil. For those soils the critical moisture content was found to be 23.72 per cent.

\section{Materials and Method}

The physical, chemical and mechanical properties of soil affecting the design analysis of Pokkali paddy harvester were studied. The four major soil properties, viz, moisture content, bulk density, shear strength and soil resistance affecting the traficability to the pokkali paddy harvester were determined in the present study. Soil samples from different locations of the Pokkali fields were collected in containers to determine the above mentioned properties of the soil. The tests were conducted in the Soil and Water Laboratory at RRS, Vytila and KCAET, Tavanur.

\section{Moisture content}

Moisture content $(\mathrm{W})$ is the ratio of the weight of water to the weight of the solids. The moisture content of the sample in per cent dry basis was determined by using the equation,

$\operatorname{MC}(\%)=\frac{W i-W d}{W i} \times 100$

Where,

$\mathrm{W}_{\mathrm{i}}$ is initial weight of the soil, $\mathrm{g}$

$\mathrm{W}_{\mathrm{d}}$ is dry weight of the soil, $\mathrm{g}$

It is expressed in percentage and is found out by oven dry method. Soil samples of six different locations of the Pokkali fields were collected at depths of $10-20 \mathrm{~cm}$. The soil samples of $350 \mathrm{~g}$ each were collected in different containers and placed in a hot electric oven under controlled temperature of $105^{\circ} \mathrm{C}$ for a time period of 24 hours (Angelis, 2007). The weight before and after drying was found out using an electronic weighing balance having a sensitivity of $0.01 \mathrm{~g}$. The determination of soil moisture content helped to find out water requirement.

\section{Bulk density}

The compactness of the soil is determined by measuring bulk density using core cutter method. The bulk density was found out by using the equation,

Bulk density $(\rho)=\frac{M}{V}$

Where,

$\rho$ - Bulk density, $\mathrm{g} \mathrm{cm}^{-3}$

$\mathrm{M}$ - Mass of the soil, $\mathrm{g}$

$\mathrm{V}$ - Volume of the soil, $\mathrm{cm}^{3}$

Initially volume of a cylinder $\left(\mathrm{cm}^{3}\right)$ was determined by measuring the internal diameter $(10 \mathrm{~cm})$ and height of core cutter $(12.5 \mathrm{~cm})$. The weight of the empty core cutter was also measured.

\section{Shear strength}

Shear strength of a soil is the maximum resistance offered by the soil to shearing stresses (Awadhal and Singh, 1985) ${ }^{[4]}$. The Shear strength was found out by using the equation,

$S=\frac{T}{\pi\left(\frac{D^{2} H}{2}+\frac{D^{3}}{6}\right)}$

Where,

$\mathrm{S}=$ Shear strength, $\mathrm{kg} \mathrm{cm}^{-2}$

$\mathrm{T}=$ Torque, kgf.cm

$\mathrm{D}=$ Overall diameter of vane, $\mathrm{cm}$

$\mathrm{H}=$ Height of the vane, $\mathrm{cm}$

If $\mathrm{H}=2 \mathrm{D}$ the equation reduces to

$S=\frac{3 T}{11 D^{3}}$

The in-situ measurement of shear strength of soil was carried out using a vane shear test apparatus (Make - AIMIL (CIVIL)) arrangement as shown in Plate 3.1. Bore holes at depths of 30, 45 and $60 \mathrm{~cm}$ were dug out. Casing was extended up to these depths and hence the entire unit was fixed at the location during the test. Torque applicator was fixed on the stand with the help of spikes. A vane size of 37.5 $\mathrm{mm}$ diameter was selected and it was connected to the vane rod having same female thread. The vane was lowered to the above required depths. It was pushed downward with a moderate steady force up to a depth of $50 \mathrm{~mm}$ below the bottom of the bore hole and allowed for 5 minutes after the insertion of the vane. The initial dial gauge reading was set to the zero and gear handle was turned so that the vane was rotated at the rate of $0.1^{\circ}$ per second, this in turn help to get a uniform rate of 12 turns per minute. Vane was rotated completely ten times to disturb the soil. Torque indicator dial gauge reading was noted at half minute interval and rotation of vane was continued until the reading drops appreciable from the maximum.

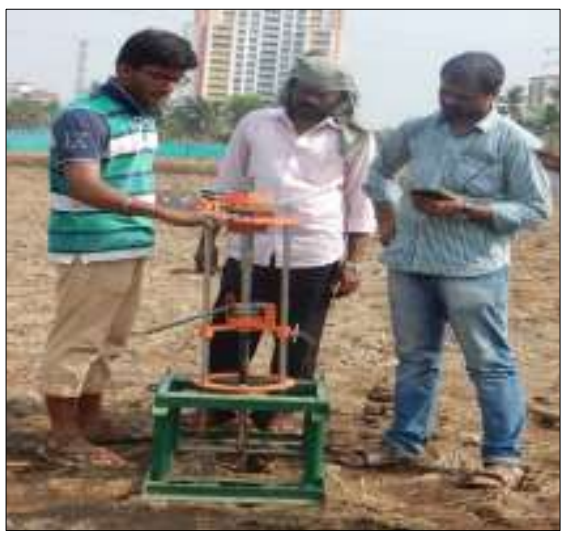

Fig 1: In-situ measurement of shear strength

\section{Soil resistance}

A cone penetrometer was used to determine the degree of soil compaction resulting from the application of different tillage operations. The cone penetrometer consisted of force and depth measuring components and a conical tip for penetration into the soil. The force applied is directly read a dial gauge fitted at the top of the instrument. The depth measurement is 
preceded by the relative movement of the penetration rod and penetrometer tip as the tip is forced into the soil. The experiment was repeated 3 to 4 times at a location, 50 to 60 $\mathrm{cm}$ a part to prevent error readings because of soil disturbance. The calibration chart was used to get the penetration resistance of the soil corresponding to the dial gauge reading.

Resistance $=\frac{P F}{B A}$

Where,

$\mathrm{PF}=$ penetration force, $\mathrm{N}$

$\mathrm{BA}=$ soil depth, $\mathrm{cm}$

Penetration force $(\mathrm{PF})=\mathrm{PR} \times 0.0098$

$\mathrm{PR}=$ mean dial gauge reading, $\mathrm{N}$

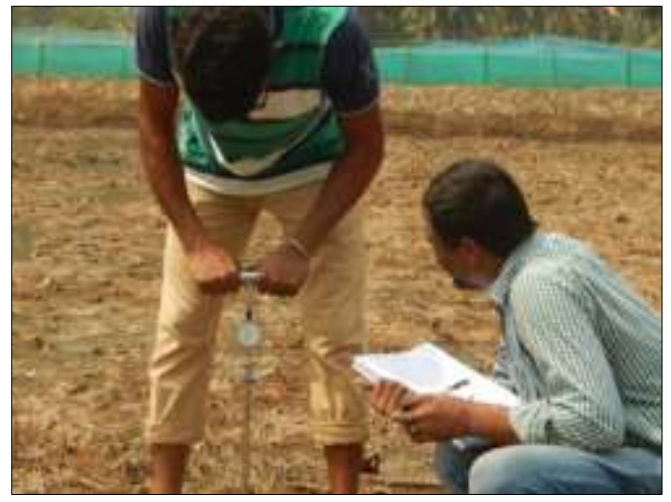

Fig 2: Measurement of soil resistance

\section{pH}

$\mathrm{pH}$ testing is used to determine the acidity or alkalinity of the subsurface or surface water environments. Acidic or alkaline environments have the potential for aggressively corroding structures placed within these environments. Soil samples collected during the normal course of a subsurface exploration should be used for $\mathrm{pH}$ testing. The NYSDOT $\mathrm{pH}$ analysis is outlined in the Geotechnical Engineering Bureau's Test Method for the Determination of $\mathrm{pH}$ of Water or Soil by $\mathrm{pH}$ Meter (GTM-24).

\section{Statistical Model}

A simple regression model proposed by Reece (1971) was used to represent the mathematical relationship between shear stress, cone penetrometer resistance, shear vane and direct shear stress at different moisture contents.

Fmax $=\mathrm{AC}+\mathrm{W} \tan \varphi$ dividing both sides by $\mathrm{A}$
$\tau=\mathrm{C}+\sigma \tan \varphi$

Where,

Fmax $=$ Maximum tractive force $(\mathrm{N})$

$\mathrm{A}=$ Area occupied by soil sample $\left(\mathrm{m}^{2}\right)$

$\mathrm{C}=$ Soil cohesion force $\left(\mathrm{kN} / \mathrm{m}^{2}\right)$

$\mathrm{W}=$ Applied load $(\mathrm{kN})$

$\varphi=$ Angle of shearing resistance $(\theta)$

$\tau=$ Shear stress $\left(\mathrm{N} / \mathrm{m}^{2}\right)$

$\sigma=$ Normal stress $\left(\mathrm{N} / \mathrm{m}^{2}\right)$

\section{Results and Discussion}

Fig 2 shows the results obtained with the use of the cone penetrometer on the Pokkali soil samples. The cone index decreases with increases soil depth. The reason is because the moisture content increases as the depth increases for $10 \mathrm{~cm}$, $15 \mathrm{~cm}$ and $25 \mathrm{~cm}$ soil depths. As the soil depth increases the soil structure becomes more stable, thereby resisting the cone penetration. Fig 4 shows the variations obtained when shear vane apparatus was used for different soil depths. Fig 4 and 5 shows a progressive decreases in shear strength with increase in soil depth. The factor responsible for the increase in shear force is the same as the responsible for that of cone index that is decrease in soil moisture content leading to the increase in compaction. Fig 6 shows that the cone index increases with decreases the moisture content. Fig. 7 shows that the cone index and the shear strength at the different depths, depend primarily on the nature and particle arrangement of the soil. The estimated cone index and shear strength decreases with increase in depth and moisture content. Beyond the critical moisture con tent, harvesting practice becomes leading to high slippage, sinkage of machinery and loss of trafficability. For efficient harvesting, moisture content beyond the critical value needs to be drained before harvest. In Table 1, shows that the physical properties of the Pokkali soil and Table 2, shows that the chemical properties of Pokkali soil. The factor responsible for design of float in the Pokkali harvester. The selection of grouser material and shape, it's based on the type of soil, forces and chemicals present in the soil. Two statistical regression models produced from Figures 3 and 4 stated as follows:

$$
\begin{aligned}
& Y=-0.2184 X+26.06 \\
& R^{2}=0.5714 \\
& \text { For cone index, and } \\
& Y=-3 E-05 X+0.006 \\
& R^{2}=0.2266
\end{aligned}
$$

For shear vane

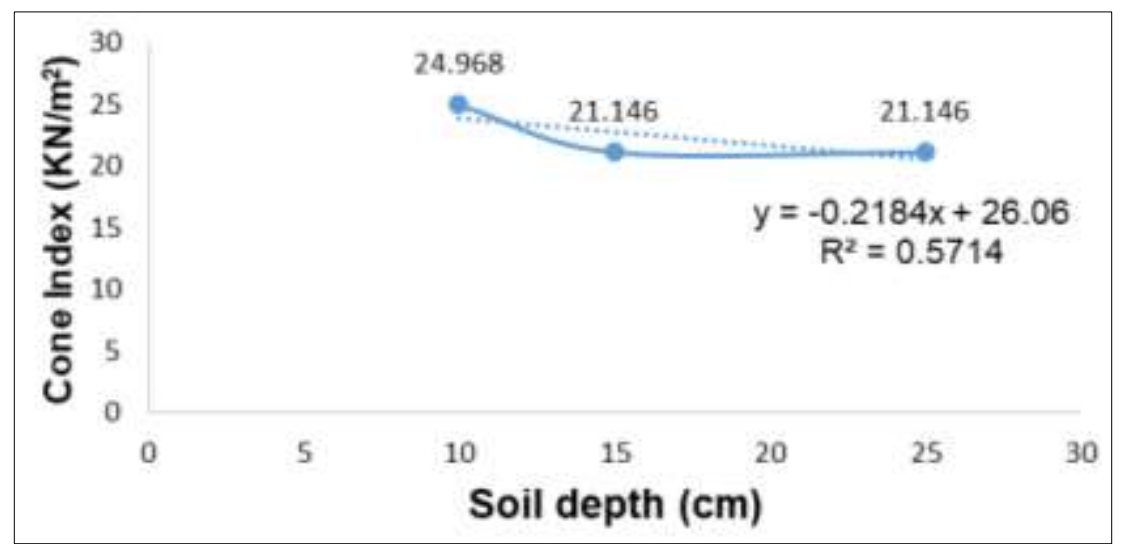

Fig 3: Relationship between cone index and soil depth 


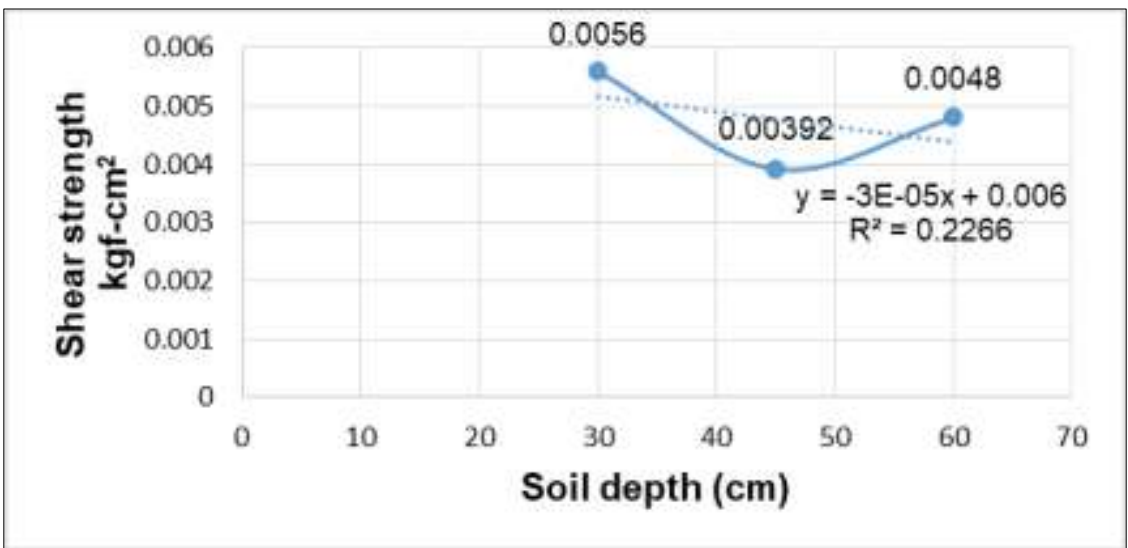

Fig 4: Relationship between shear strength and soil depth

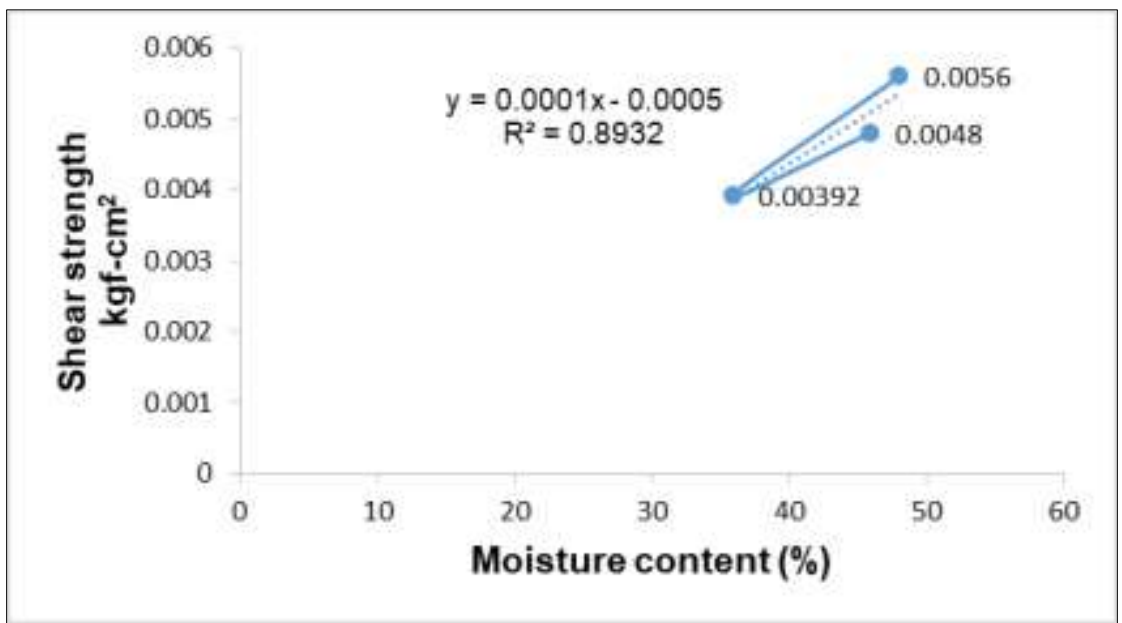

Fig 5: Relationship between shear strength and moisture content

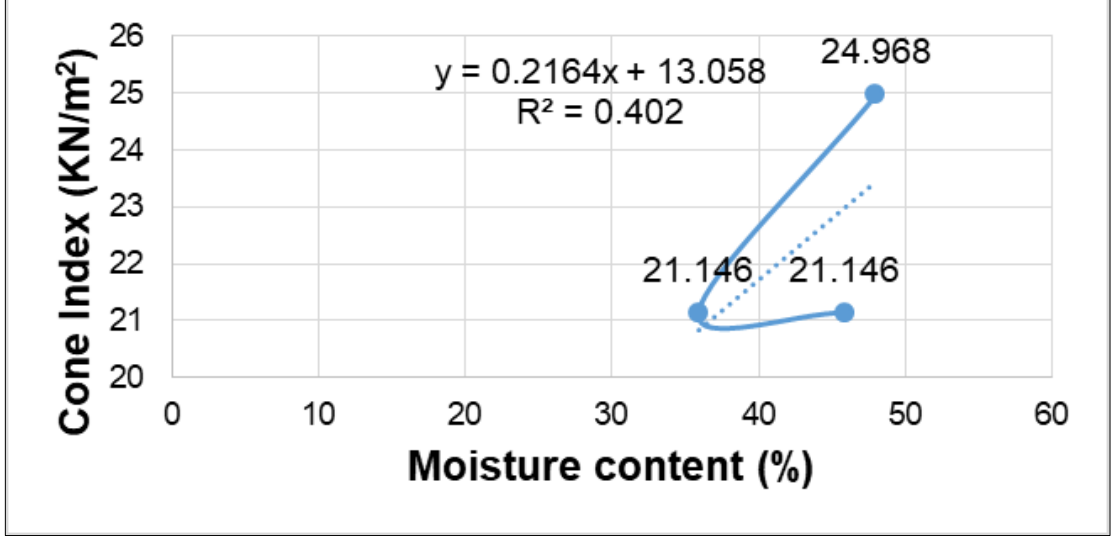

Fig 6: Relationship between cone index and moisture content

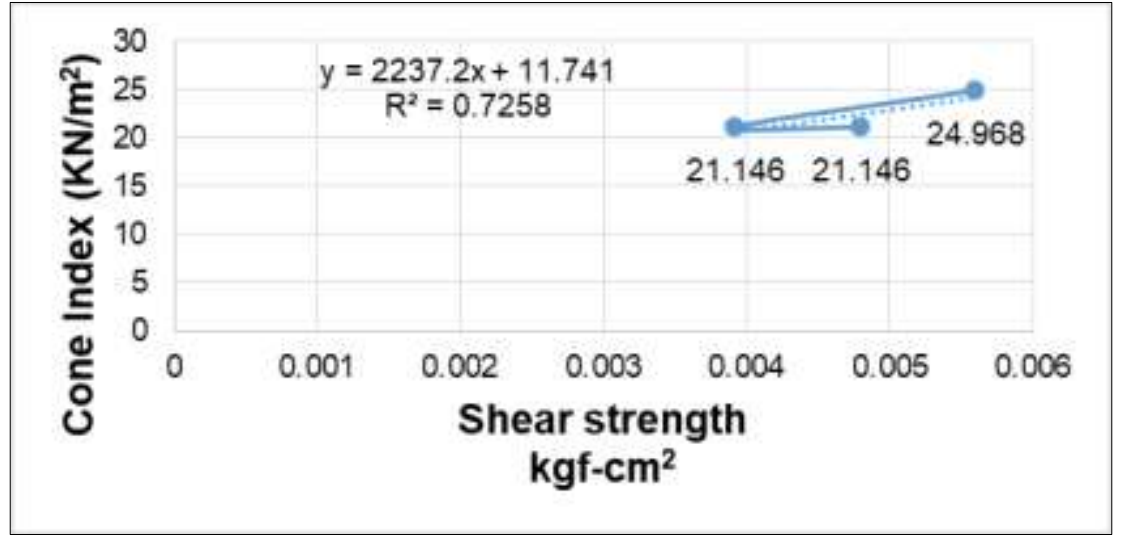

Fig 7: Relationship between cone index and shear strength. 
Table 1: Determination of physical properties of Pokkali soil

\begin{tabular}{|c|c|}
\hline Clay\% & 59.82 \\
\hline Silt\% & 17.72 \\
\hline Coarse sand\% & 4.14 \\
\hline Fine sand \% & 18.51 \\
\hline Texture & Clay \\
\hline Bulk density Mg m-3 & 0.71 \\
\hline
\end{tabular}

Table 2: Determination of chemical properties of Pokkali soil

\begin{tabular}{|c|c|c|c|c|c|c|c|c|c|c|c|c|c|}
\hline & & & \multicolumn{11}{|c|}{ Available nutrients } \\
\hline pH & EC & OC & $\mathbf{N}$ & $\mathbf{P}$ & $\mathbf{K}$ & $\mathrm{Fe}$ & $\mathrm{Cu}$ & $\mathbf{Z n}$ & Mn & B & $\mathbf{C a}$ & $\mathbf{M g}$ & $\mathbf{S}$ \\
\hline & $\mathrm{dS} / \mathrm{m}$ & $(\%)$ & Kg/ha & kg/ha & Kg/ha & $\mathrm{mg} / \mathrm{kg}$ & $\mathrm{mg} / \mathrm{kg}$ & $\mathrm{mg} / \mathrm{kg}$ & $\mathrm{mg} / \mathrm{kg}$ & $\mathrm{mg} / \mathrm{kg}$ & $\mathrm{mg} / \mathrm{kg}$ & $\mathrm{mg} / \mathrm{kg}$ & $\mathrm{mg} / \mathrm{kg}$ \\
\hline 4.69 & 0.48 & 1.86 & 110.39 & 68.3 & 105.9 & 869.4 & 0.6016 & 0.5744 & 33.21 & 0.419 & 152.9 & 11.951 & 15.105 \\
\hline
\end{tabular}

\section{Conclusion}

The study shows that the cone index and shear strength of Pokkali soils decreased with increased depth and decreased with increase in moisture content. For this soil the critical moisture content was found to be $45.9 \%$.

\section{Reference}

1. Abhilash Joseph E. Rice cultivation in saline tracts of Kerala. Int. J. of Fish. and Aquat. Stud 2016;4(4):355358.

2. Adeniran KA, Babatunde OO. Investigation of Wetland Soil Properties affecting Optimum Soil Cultivation. J. of Eng. Sci. and Technol 2010,23-26p.

3. Agodzo SK, Adama I. Bulk density, cone index and water content relations for some ghanaian soils. Kwame Nkrumah Univ. Sci. Technol. Kumasi-Ghana 2003,6-8p.

4. Awadhal NK, Singh CP. Dynamic behaviour of wet soil, tillage and traction in wet soil. Agric. Mechanisation in Asia, Afr. and Latin Am 1985;16(2):11-90.

5. Blake GR, Hartge KH. Methods of soil analysis. Part 1, physical and mineralogical methods. 2nd ed., Agronomy Monograph No. 9. Madison, WI: Soil Sci. Soc. of Am 1986,363-375p.

6. Brandelik A, Hibner C. Soil moisture determination accurate, larger and deep. Phys. Chem. Earth 1996;21(3):157-160.

7. Geotechnical Design Manual. NYSDOT geotechnical. 2013;6:1

8. Jackson ML. Soil Chemical Analysis (Indian Reprint, 1967). Prentice Hall of India Private Ltd., New Delhi 1958,498p.

9. Reece AR. The shape of the form tractors, J. of Agric. Engg 1971;26(4):20-24. 